\title{
Coping Strategies Among Spouses of Alcohol dependents at Gokarneswor, Kathmandu, Nepal
}

\author{
Srijana Pandey*, Kalpana Shrestha
}

Nepal Medical College, Nepal

\section{Article Info}

\section{Article Notes}

Received: September 28, 2019

Accepted: January 6, 2020

\section{*Correspondence:}

Srijana Pandey, Masters in Psychiatric Nursing, Lecturer, Nepal Medical College, Nepal; Email: srijanapandey2036@gmail.com.

(C) 2020 Pandey S. This article is distributed under the terms of the Creative Commons Attribution 4.0 International License.

\section{Keywords}

Coping level

Coping strategies

Coping subscale

Spouses

Alcohol dependents

Gokarneshwor

Kathmandu

Nepal
Abstract

Introduction: Alcoholism is characterized by an increased tolerance of and physical dependence on alcohol, affecting an individual's ability to control alcohol consumption safely. Worldwide, researchers have been focusing on the effect of alcohol use on the family and children, which interact to diminish the individual's ability to adapt leading to distress.

Methods: This was a descriptive cross-sectional study with convenience sampling technique in which cage questionnaire was used to identify the alcoholic family and interviewed 162 spouses of alcoholics at Gokarneswormunicipality, Kathmandu, Nepal

Findings: The study revealed that coping level among spouses of alcoholics was average that was $98.1 \%$ and well was lowest that was $1.8 \%$. The coping strategies used was in three subscales engaged coping, withdrawal coping and tolerant coping. In three subscale, withdrawal coping scored highest $(55.57+6.74)$ and engaged coping scored lowest $(24.61+3.43)$. There was a significant association between level of coping with the duration of alcohol intake and there was no association with other socio-demographic variables such as age, education, occupation, marriage, type of family, no. of children. Conclusion: The study showed the average coping level and three ways of coping strategy that was withdrawal coping, engaged coping and tolerant coping. Most of the respondents used withdrawal coping. The study recommends the research on identification of alcohol abusers at community and provide early treatment and counselling to the family.

\section{Background/Introduction}

Alcoholism generates tolerance of and physical dependence on alcohol as well as individual's ability to control alcohol consumption which affects individual family and society ${ }^{1}$. The effects of alcohol abuse can cause more damage and pain than any other internal or external influence on the family unit ${ }^{2}$. On the other hand, public intervention on this issues has proved useful: a rapid evidence review of the impact of pricing and taxation policies on alcohol-related crime outcomes identified that alcohol tax and price increases were associated with reductions in overall crime, violent crime, sexual assault and criminal damage/property offences ${ }^{3}$. This study can be applied to economic valuation studies that aim to measure the benefits of programs intended to reduce the prevalence of alcohol dependence ${ }^{4}$.

Caregiver's burden is a multi-dimensional phenomenon reflecting physical, psycho-emotional, social and financial consequences of caring for an impaired family member ${ }^{5}$. The alcoholism effects may directly or indirectly drain out caregivers of substance abusers. The magnitude from harm to people other than the drinker, therefore the overall economic burden of risky alcohol consumption across 
countries is underestimated ${ }^{6}$. Alcohol dependence not only reduces life expectancy, but also causes considerable loss of quality of life of the dependents of and persons around those with alcohol dependence ${ }^{7}$. Equally alarming, studies show that alcohol abuse seems to be one of the most important driving factors in the transmission of violence across contexts and social relationships-from war-violence to community-violence and from being a victim of war or intimate partner violence (IPV) to being a perpetrator of violence against children ${ }^{8}$.

One of the most affected among caregivers is the marital partners ${ }^{9}$. Spouses are particularly affected by constant exposure to the behavior of the alcoholic. The negative social consequences of alcohol consumption and stressful life events may trigger psychological, biological, behavioral responses, which interact to diminish the individual's ability to adapt ${ }^{10}$. Spouse of alcoholics is faced with many problems like mental and physical problems, lack of communication between others, financial problems, marital violence, damage to social reputation, libido towards sexual performance ${ }^{11,12}$. The wives of persons with alcoholism are known to have significant problems such as marital dissatisfaction, poor social interaction, communication problems, physical problems, and mental health disorders ${ }^{12}$.

Globally, the majority of those who need mental health care worldwide lack access to high-quality mental health services. Stigma, human resource shortages, fragmented service delivery models, and lack of research capacity for implementation and policy change contribute to the current mental health treatment gap ${ }^{13}$. While studying this aspect due consideration may be given to family dynamics to include the modifying effect of other family members ${ }^{14}$.

Avoidance, discord, fearful withdrawal and sexual withdrawal were the most common coping components identified among wives of alcoholics ${ }^{15,17}$. The nature of coping behavior of them depends on the personality, degree of duration of her husband's alcoholism and duration of marriage. Jones A. Jackson et al. (1954) (27) first propounded the 'stress model'16. The coping mechanisms characteristic of alcoholic women relative to their nonalcoholic controls. The profile of coping strategies utilized by the alcoholic group is consistent with a poor quality of life and compounding of problems ${ }^{17}$. Alcoholism affect emotionally, physically, socially and psychologically. Spouses feel difficult to manage her married life and feel stress $^{18}$. Engaged coping is a form of coping in which the wife of alcoholic gets vigorously engaged with an alcoholic husband through active interaction may be arguing with them to try them to stop, throwing away their drinks, telling the user that their behavior was having a negative effect on them. The withdrawal coping involves avoidance of the drinker, active involvement in other self-regulating activities and gaining independence. Tolerant coping is inactive coping by putting up with the problem ${ }^{19}$. A coping mechanism is something that helps a person deal with something that is difficult for them. While, all coping mechanisms provide the person using them with a real or perceived benefit, some coping mechanisms have more negative consequences associated with them ${ }^{20}$.

The current study aims to research the coping strategies among spouses of alcoholics in a small population in a municipality of Gokarna TM, Kathmandu, Nepal.

\section{Materials and Methods}

Research design: Descriptive, exploratory and cross sectional design

Area of study: Ward no.4, Gokarneswor- Municipality, Kathmandu, Nepal.

Study population: Spouses of alcohol dependents residing in their own house. Step-1:visiting each household. Step-2 : identification of alcohol dependents using cage questionnaire. The questions include Yes and No response. Each Yes response scores 1 and No scores 0 .Two yes response will be considered alcohol dependent /abuse.Step-3:interview.

Sampling technique: Convenience sampling technique was used followed by cage questionnaire.

Sample size:173 Spouses

$\mathrm{n}=$ required sample size

$\mathrm{Z}=$ confidence level at 95\%(standard value is 1.96)

$\mathrm{P}=$ prevalence of alcohol dependent

$\mathrm{q}=67$

$\mathrm{d}=$ allowable error

$\frac{\mathrm{n}=\mathrm{Z}^{2} \mathrm{pq}}{\mathrm{d}^{2}}=\frac{(1.96)^{2} \times 33 \times 67=3.84 \times 33 \times 67}{(7)^{2}}=\frac{8,490.24}{49}=173.27$

\section{Variable}

- Dependent variables: Coping strategies

- Independent variables: Age ${ }^{19}$, gender, education, occupation, socio-economic status, religion, family income, type of family, duration of marital life, no of children, duration of spouses alcoholism.

- Inclusion criteria : Wives of alcoholics . Who are willing to participate.

- Exclusion criteria: Wives whose husbands had poly substance abuse other than alcohol and nicotine.

- Research instrument (Tools):

A. Demographic information

B. Modified tools of standard Coping questionnaire. 


\section{Data collection procedure}

Step-1:visiting each household. Step-2: identification of alcoholics using cage questionnaire ${ }^{25-29}$. Step-3:interview. Modified tools of standard Coping questionnaire developed by Orford, J., Templeton, L., Velleman, R. and Copello, A. (2005). Modified version of coping questionnaire include 21 items. Each item scores as $\mathrm{No}=0$, once/twice $=1$, sometimes $=2$, Often $=3$.I choosed this item in context to Nepal. Pre-testing was done in the similar setting and it was reliable. First coping level was identified from overall questionnaire as: well coping, average coping and poor coping. Therefore, chi-square test was used to see the relationship of coping level with independent variables. Then, mean for each subscale of coping was calculated as an average score from total score obtained by the participants in each subscale that is engaged coping, tolerant coping and withdrawal coping.

A written consent was obtained from the participants regarding their willingness to participate in the study. A formal administrative permission was obtained from the authorities of the proposed settings. The data was entered in SPSS 16. In statistical analysis, descriptive analysis was used. After completing the data, the cases was taught about coping strategies and refer the alcohol dependent for counseling and treatment.

\section{Results}

The majority of respondents were from age group 56-70 years $(59.25 \%)$ and least were from $18-35$ years $(12.96 \%)$. Most of the respondents education level was illiterate that was 40.12 and who obtained higher secondary education was $9.25 \%$. Majority of the respondents occupation was agriculture (33.33\%) and service holder were (2.46\%). In Nepal less person have children more then three so researcher ought to classify the number of children as less then three and more than three. Most of the respondents number of children were less then three that was $88.88 \%$. The repondents whose number of children more than three were $11.11 \%$. Majority of respondents belong to nuclear family (60.49\%). The respondents who belong to extended family were less(1.23\%).Twenty eight percent of respondents were married for $11-20$ years and 3.08\% were for 41-50 years. The duration of alcohol intake among spouses for $1-10$ years was $43.20 \%$ and for $41-50$ years was .6\% (Table 1 ).

The study revealed that coping level among spouses of alcoholics was average coping ( $98.1 \%$ ) and well coping was lowest that was $1.9 \%$ (Table 2). The coping strategies used was in three subscales; among them withdrawal coping scored highest (55.57_+6.74) and engaged coping scored lowest $\left(24.61 \_+3.43\right)$ (Table 3). There was a significant
Table.1: Information of the respondents

\begin{tabular}{|c|c|c|}
\hline Variables & Frequencies & Percentage \\
\hline $\begin{array}{l}\text { Age } \\
18-35 \\
36-55 \\
56-70\end{array}$ & $\begin{array}{l}21 \\
45 \\
96\end{array}$ & $\begin{array}{l}12.96 \% \\
27.77 \% \\
59.25 \%\end{array}$ \\
\hline $\begin{array}{l}\text { Education } \\
\text { Primary } \\
\text { Secondary } \\
\text { Higher secondary } \\
\text { Illiterate }\end{array}$ & $\begin{array}{l}42 \\
40 \\
15 \\
65\end{array}$ & $\begin{array}{c}25.92 \% \\
24.69 \% \\
9.25 \% \\
40.12 \%\end{array}$ \\
\hline $\begin{array}{l}\text { Occupation } \\
\text { Business } \\
\text { Agriculture } \\
\text { Service } \\
\text { Labour } \\
\text { Others }\end{array}$ & $\begin{array}{c}37 \\
54 \\
4 \\
20 \\
47\end{array}$ & $\begin{array}{c}22.83 \% \\
33.33 \% \\
2.46 \% \\
12.34 \% \\
29.01 \%\end{array}$ \\
\hline $\begin{array}{l}\text { Duration of Marriage } \\
1-10 \text { yrs } \\
11-20 y r s \\
21-30 y r s \\
31-40 y r s \\
41-50 y r s\end{array}$ & $\begin{array}{c}33 \\
46 \\
44 \\
34 \\
5\end{array}$ & $\begin{array}{c}20.37 \% \\
28.39 \% \\
27.16 \% \\
20.98 \% \\
3.08 \%\end{array}$ \\
\hline $\begin{array}{l}\text { Number of children } \\
<3 \\
\text { More then equal to } \\
\text { 3children }\end{array}$ & $\begin{array}{c}144 \\
18\end{array}$ & $\begin{array}{c}88.88 \% \\
11.1 \%\end{array}$ \\
\hline $\begin{array}{l}\text { Type of family } \\
\text { Nuclear } \\
\text { Joint } \\
\text { Extended }\end{array}$ & $\begin{array}{c}98 \\
62 \\
2\end{array}$ & $\begin{array}{c}60.49 \% \\
38.27 \% \\
1.23 \%\end{array}$ \\
\hline $\begin{array}{l}\text { Duration of alcohol } \\
\text { intake of spouses } \\
1-10 \text { yrs } \\
11-20 y r s \\
21-30 y r s \\
31-40 y r s \\
41-50 y r s\end{array}$ & $\begin{array}{c}70 \\
49 \\
37 \\
4 \\
1\end{array}$ & $\begin{array}{c}43.20 \% \\
30.24 \% \\
22.83 \% \\
2.46 \% \\
0.61 \%\end{array}$ \\
\hline
\end{tabular}

$\mathrm{N}=162$

Table.2: Level of coping

\begin{tabular}{|l|c|c|}
\hline Level of coping & Frequency & Percent \\
\hline Average & 159 & 98.14 \\
\hline Well & 3 & 1.85 \\
\hline Total & 162 & 100 \\
\hline
\end{tabular}

Table.3: Aspects(subscales) wise Mean Coping Scores

\begin{tabular}{|l|c|c|c|c|}
\hline \multirow{2}{*}{ Aspects(subscales) } & \multirow{2}{*}{ Min. Score } & \multirow{2}{*}{ Max. Score } & \multicolumn{2}{|c|}{ Respondents } \\
\cline { 3 - 5 } & & Mean & SD \\
\hline Engaged coping & 13 & 32 & 24.61 & 3.43 \\
\hline Tolerant coping & 27 & 65 & 50.12 & 2.30 \\
\hline Withdrawal coping & 35 & 70 & 55.57 & 1.79 \\
\hline
\end{tabular}

association between levels of coping with the duration of alcohol intake and there was no association with other socio-demographic variables as age, education, occupation, marriage, type of family, no. of children(table 4). 
Table.4: Association of respondent's coping level and selected demographic variables

\begin{tabular}{|c|c|c|c|}
\hline \multirow{2}{*}{ Variable } & \multicolumn{2}{|r|}{ Level of coping } & \multirow[b]{2}{*}{$p$-value } \\
\hline & Well coping & Average coping & \\
\hline $\begin{array}{l}\text { Age } \\
18-35 \text { yrs } \\
36-55 y r s \\
56-70 y r s\end{array}$ & $\begin{array}{l}0 \\
1 \\
2\end{array}$ & $\begin{array}{l}21 \\
44 \\
94\end{array}$ & .795 \\
\hline $\begin{array}{l}\text { Education } \\
\text { primary } \\
\text { secondary } \\
\text { Higher secondary } \\
\text { illiterate }\end{array}$ & $\begin{array}{l}0 \\
1 \\
0 \\
2\end{array}$ & $\begin{array}{l}42 \\
39 \\
15 \\
63\end{array}$ & .636 \\
\hline $\begin{array}{l}\text { Occupation } \\
\text { Business } \\
\text { Agriculture } \\
\text { Service } \\
\text { Labour } \\
\text { Others }\end{array}$ & $\begin{array}{l}0 \\
1 \\
0 \\
1 \\
1\end{array}$ & $\begin{array}{c}37 \\
53 \\
4 \\
19 \\
46\end{array}$ & .757 \\
\hline $\begin{array}{l}\text { Types of family } \\
\text { Nuclear } \\
\text { Joint } \\
\text { Extended }\end{array}$ & $\begin{array}{l}1 \\
2 \\
0\end{array}$ & $\begin{array}{c}97 \\
60 \\
2\end{array}$ & .590 \\
\hline $\begin{array}{l}\text { Duration of alcohol } \\
\text { intake of spouses } \\
1-10 \\
11-20 \\
21-30 \\
31-40 \\
41-50\end{array}$ & $\begin{array}{l}0 \\
1 \\
1 \\
1 \\
0\end{array}$ & $\begin{array}{c}70 \\
48 \\
37 \\
3 \\
1\end{array}$ & .010 \\
\hline
\end{tabular}

$\mathrm{N}=162$

\section{Discussions}

Alcoholism is increasing problem and family has been in problem which have impact on people around him. This study showed that level of coping was average coping that was $98.14 \%$. Similar result was found where coping level was average $30(42.86 \%)$ in a study done by Mrs. Devi C.G, Rajasankar, Kokilavani $\mathrm{N}^{17}$.

In this study, Coping strategies used by spouses of alcoholics were in three major styles: engaged, tolerant and withdrawal coping. This study is in coherence with the study done in India ${ }^{19,21}$.

This finding of the study showed that they used more withdrawal coping and found that there was association between level of coping with the duration of alcohol intake of spouses which was contrary to findings from a study done by R t.s. Sathyanarayana and K Kuruvilia ${ }^{22}$.

In this study, most of them used withdrawal coping and then tolerant coping and very few used engage coping. This finding is contrary to the findings mentioned in subscales of coping as study done by Sharma et $\mathrm{al}^{23}$. The study found most of them used engaged coping(93\%),one fourth used withdrawal coping and very few $6 \%$ used tolerant coping.

This study finding recommends women should be taught to use more active coping as the study was done by Solomon, Laura J.; Rothblum, Esther D ${ }^{24}$.

Coping strategies used was average coping among age group of 56-70 years and less of them were from age group 18-35 years, Most of the illiterate 63 of them used average coping and less number of educated in higher secondary 15 of them used average coping. The findings of the study helps to screen the alcohol abusers, provide counseling to the spouses and early referral.

The results of this study need to be considered in relation to its limitations. The major limitation of this study was its small sample size and cannot be generalize.

Principal Investigator: Overall Proposal preparation, budgeting, assignment, checking data and analysis, report preparation and submission. Supervises the RA. Training to data collectors.

Co-investigator: Preparation of proposal, Training to research assistant, Supervisor, Initiates the assignment and report writing. Supervises the RA.Training to data collectors.

Acknowledgements: Authors are thankful to respondents, directly and indirectly who helped me in this research.

\section{References}

1. Kaur D, Ajinkya S. Psychological impact of adult alcoholism on spouses and children. Med J DY PatilUniv. 2014; 7: 124-127.

2. Lakshmana G, Pankajakshi B. A community study on violenc among wives of alcoholics. J Delhi psychiat. 2014; 17: 1-5.5

3. Andrew B, Meier P, Shapland, et al. Alcohol pricing and criminal harm:a rapid evidence assessment of the published research literature. School of health and related research(ScHARR),The university of Sheffield.Available from: ias.org.uk.12

4. MosqueraNogueiraJ, Rodriguez-MiguezE. Intangible costs of alcohol dependence from the perspective of patients and their relatives $\mathrm{A}$ contingent valuation study. Addicciones. 2018; 30(2): 111-122.13

5. Abozead EI-Sayead S, Senthil M, Manisha K. Family interaction pattern among caregivers of patients with epilepsy and alcohol dependence. IOSR JHSS. 2015; 20(9): 1-09. Retrived from:semanticscholar.org 6

6. Navarro HJ, Doran CM, Shakeshaft AP. Measuring costs of alcohol harm to others: A review of the literature. Drug and alcohol depend. 2011; 114(2): 87-9910.

7. Nogueira JM, Rodríguez-Míguez E. Using the SF-6D to measure the impact of alcohol dependence on health-related quality of life. Eur J Health Econ. 2015; 16(4): 347-56.

8. Global Perspectives Excessive Alcohol Use In Crisis-affected Societies A Weak Spot of Global Mental Health Research and Practice. https: //istss.org/public-resources/trauma-blog/2016-october/globalperspectives-excessive-alcohol-use-in-crisis11

9. Banerjee I, Bora D, Deuri PS. Coping Strategies and Perceived Social Support in Wives of Persons with Alcohol Dependence Syndrome. Indian J PsySocl Work. 2017; 8: 28-32 16.

10. Kishor M, Pandit VL, Raguram R. Psychiatric morbidity and marital satisfaction among spouses of men with alcohol dependence. Indian J Psychia. 2013; 55: 360-3657. 
11. Level of stress and coping among spouse of alcoholics. NNJ. 2016; 5: 36-388.

12. Johnson PR, Britto C, Sudevan KJ, et al. Resilience in Wives of personswith Alcoholism: An Indian exploration. Indian J Psychiatry. 2018; 60: 84-915.

13. WainbergLM, ScorzaP, Shultz MJ, et al. Challenges and opportunities in global mental health: a research to practice perspective. CurrPsychiat Rep. 2017; 19(5): 2814.

14. Chandrasekaran R, Chitraleka V. Patterns and determinants of coping behaviour of wives of alcoholics. Indian J Psychiat. 1998; 40 (1): 30-3417.

15. Nanjundaswamy M, Sreedevi PA, Gangadharaiah HM, et al. A study to assess the stress, coping strategies and domestic violence in wives of alcohol dependent individuals. Eur psych. 2013; 28: 1.

16. Dr B Shanthi1, Dr K Veeramuthu MD, DPM. A Study of Female Spouses of Male Alcohol Dependence Patients. IOSR-JDMS. 2017; 16(3): 127-145.

17. RaoTS, Kkuruvilia. A study on the coping behaviours of wives of alcoholics. Indian J Psychiat. 1992; 34: 359-365.

18. Philip J, Michels N, Peter Johnson, et al. Coping Strategies of Alcoholic Women.1999; 20(4): 237-248.

19. Savita, Sulekha, Dadwal S, et al. Level of stress among spouses of alcoholic men. 2014; 3(4): 1-4.
20. Retrieved from: https://www.sandstonecare.com/resources/ substance-abuse/alcohol/alcohol-use-as-a-coping-mechanism

21. Barman H. Coping strategies used by wives of patients with alcohol related disorders. IJNER. 2019; 7(2): 25.

22. Devi CG, Rajasanskar, Kokilavani N. A study to assess the level of stress and coping strategies among wives of alcoholics at selected settings. International Journal of Nursing education and Research.2013; 1: 12-1320.

23. Nitashasharma, Sunitasharma, Sandhyaghai, et al. living with an alcoholic clients. J Ind psych. 2016; 25: 65-7122.

24. Solomon, Laura J, Rothblum, et al. Stress, coping, and social support in women. The Behavior Therapist. 1986; 9: 199-20424.

25. Retrived from: Source Dr John Ewing founding Director of the Bowles Center for Alcohol Studies University of North Carolina at Chapel Hill

26. Retrieved from: https: $\mathrm{z} / /$ www.healthline.com/health/cagequestionnaire

27. Retrieved from:https://www.hopkinsmedicine.org

28. Retrived from: https://www.fadap.org

29. Retrieved from:https://www.uspreventiveservicestaskforce.org 